\title{
Underlying factors related to errors in financial mathematics due to incorrect or rigidity of thinking \\ $X$ KHALO ${ }^{1}$ AND A BAYAGA
}

\begin{abstract}
The main aim of the study was (1) to identify the underlying factors related to errors due to incorrect association, and (2) to understand why learners continue to make such errors so that mechanisms to avoid such errors could be devised.

The study was conducted by means of a case study guided by the positivists' paradigm where the research sample comprised of 105 Grade 10 Mathematics Literacy learners as respondents. Having used Polya's problem-solving techniques, Threshold Concept and Newman's Error Analysis as the theoretical frameworks for the study, a four-point Likert scale and a content-based structure-interview questionnaire were developed to address the research question. Four sets of structured-interview questionnaires were used for collecting data, aimed at addressing the main objective of the study. In order to test the reliability and consistency of the questionnaires for this study, Cronbach's Alpha was tested for standardised items $(\alpha=0.705)$.

Once the data was collected, it was analysed through content and correlation analysis. Based on the frequency table which summarises learner responses, it could be ascertained that the majority ( $n=63,60 \%$ ) of learners admitted to sometimes confusing addition with multiplication. The relationship between learners forgetting to write units and learners writing down an incorrect number/figure revealed a significance where $p=.04(r$ $=+.17)$ illustrated a weak correlation between the afore-stated variables.
\end{abstract}

Keywords: errors; financial mathematics; incorrect association; rigidity of thinking

\section{Introduction}

Surprisingly, learners who seem to follow the trend of the lessons, commit errors when working out the tasks assigned. That stimulated the researchers to critique, understand and do research to try and find answers as to what type of errors are common among Grade 10 Mathematical Literacy (ML) learners in financial mathematics. Financial mathematics accounts for $35 \%$ weighting of the topics in the examination, which indicates that it is more valuable in ML studies. It encompasses a number of basic mathematical skills such as: interpreting, communicating answers and calculating, and calculations with numbers. This is where learners lose marks in their assessment tasks. Financial mathematics is categorised as the Application Topic which, according to DoE (2011: 13), "contain[s] the contexts related to scenarios involving daily life, workplace and business environment, and wider social,

1. This article is based on Mr Xolani Khalo's Master of Education studies in the field of Error analysis in Mathematical Literacy: case of financial mathematics. Email: x.khalo@gmail.com

2. Prof. Anass Bayaga, of the University of Zululand, has published widely both locally and internationally and has managed and coordinated both local and international projects across Africa, Europe, Asia and US in information systems risk and mathematics. Email: bayagaA@unizulu.ac.za 
national and global issues that learners are expected to make sense of content and context". It includes: financial documents, tariff systems, income, expenditure, profit/loss, income-andexpenditure statements, budget, interest, banking, loans and investments.

\section{Problem statement}

The above-mentioned synopsis suggests that learners continue to commit similar errors in their work when they are assessed even with the best teaching and learning strategies. According to Heinze \& Reiss (2007: 4), "In mathematics classroom errors and particularly the error management may play different role, depending on the mathematical activities". The researcher sought to uncover the underlying factors related to errors due to the incorrect association or rigidity of thinking. Learners are sometimes not even aware of the errors they commit. There is also a repetitive error in most of their assessment tasks throughout the year. However, there is a negligible number of South African studies on the technical know-how of error analysis in particular with regard to Grade10 Mathematical Literacy (ML).

\section{Aim of research}

The main objective of the study was (1) to explore errors that learners commit when confronted by financial mathematics questions in different forms of assessment, and (2) to develop an understanding of the reasons why learners continue to make such errors so that mechanisms to avoid such errors could be devised.

\section{Specific objective}

In light of the afore-statement, the current research sought to explore (1) the underlying factors that relate to the errors due to incorrect association or rigidity of thinking, (2) bring about the findings and the recommendation of the methods to eliminate those errors to the attention of educators as well as learners.

\section{Research question}

The study sought to answer the following research question: What is/are the underlying factor(s) related to the errors due to incorrect association or rigidity of thinking?

\section{Research hypothesis}

$\mathrm{H}_{0}$ : Errors committed by learners in financial mathematics are due to incorrect association or rigidity of thinking.

$\mathbf{H}_{1}$ : Errors committed by learners in financial mathematics are not due to incorrect association or rigidity of thinking.

\section{Literature review}

The error analysis in the education of mathematics

Error analysis is more diagnostic to determine learners' procedural effectiveness; it also allows for determining learners' lack of basic conceptual understanding. Peng (2009: 1) contends that "mathematical errors are a common phenomenon in learners' learning of mathematics. Learners of any age irrespective of the performance in mathematics have experienced getting mathematics wrong". It is essential to consider that analyzing learners' mathematical errors is 
a fundamental aspect of teaching for mathematics teachers as it will allow them to develop corrective and preventative measures.

According to Murray (2012: 55), "Many teachers complain that learners find word problems in mathematics more difficult than straight computation and that many learners dislike and even fear word problems". Mathematical Literacy is contextual based; therefore it consists mostly of word problems in its nature; which explains the existence of persisting learner errors therein.

Ryan and McCrae as cited by Sheinuk (2010: 12) state that "pre-service teachers who confront own mathematical errors, misconceptions and strategies in order to recognize their subject matter knowledge, have an opportunity to develop rich context knowledge".

Radatz (1979: 170) provides a good definition of 'error'. Firstly, errors in the learning of mathematics are not simply the absence of correct answers or the result of unfortunate accidents, they are the consequences of definite processes whose nature must be discovered. Secondly, it seems to be possible to analyze the nature and underlying causes of errors in terms of the individuals' information-processing mechanisms. Thirdly, the analysis of errors offers a variety of points of departure for research into processes by which children learn mathematics. Mathematical Literacy is also based on the same principles as mathematics, only different in purpose and nature from mathematics. Error analysis in Mathematical Literacy is based on the same principles as in mathematics; therefore the afore-stated Radatz definitions of errors are applicable to Mathematical Literacy.

According to Radatz (1979:163), "Error analysis in mathematics education has a long history that dates as far as 1925 by Buswell and Judd who cited more than 30 studies dealing explicitly with the diagnosis of Arithmetical errors". Error analysis is of vital importance in addressing the careless errors that learners commit through their learning process.

Errors are an important part of any practice because they illuminate what mechanisms need to be put in place to give access to the practice. Errors point to the demand of practice; while at the same time they are the points of leverage for opening access to the practice. To understand learner errors, one has to look at the methods or strategies that the learners use to arrive at the incorrect solutions. If teachers search for the ways to understand why learners may have made errors, they may come to value their thinking and find ways to work it into classroom conversations and bring preventative measures.

Errors can be the result of carelessness; misinterpretation of symbols or text; lack of relevant experience or knowledge related to the mathematical literacy topic/concepts; a lack of awareness or inability to check the answers given, or the result of a misconception.

By pinpointing learner errors in Mathematical Literacy, the teacher can provide instruction targeted to the learners' area of need. In general, learners who have difficulty learning Mathematical Literacy typically lack important conceptual knowledge for a number of reasons, including an inability to process information at the rate of the instructional pace; lack of adequate opportunities to respond, and the lack of specific feedback from the teacher regarding the misunderstanding cited.

Hodes adapted the following table from Nolting (1998:1) which illustrates five types of errors for word problems. 
Table 1: Types of errors for word problems

\begin{tabular}{|c|c|c|}
\hline 1. & Read errors & The learner cannot read a key word or symbol correctly. \\
\hline 2. & Comprehension errors & $\begin{array}{l}\text { The learner reads all the words in the problem accurately but } \\
\text { does not understand the overall problem or specific terms } \\
\text { within the problem. }\end{array}$ \\
\hline 3. & Transformation errors & $\begin{array}{l}\text { The learner understands what the problem requires but is } \\
\text { unable to identify the operation or the sequence of } \\
\text { operations needed to solve the problem. }\end{array}$ \\
\hline \multirow[t]{4}{*}{4.} & Procedural errors & These include: \\
\hline & & $\begin{array}{l}\text { Placement errors which is incorrect sequencing of } \\
\text { digits or alignment of algorithms. }\end{array}$ \\
\hline & & $\begin{array}{l}\text { - Incorrect steps which is use of steps that are not } \\
\text { associated with any operations. }\end{array}$ \\
\hline & & $\begin{array}{l}\text { - Missing steps where steps necessary to complete a } \\
\text { procedure are missing. }\end{array}$ \\
\hline 5. & Encoding errors & $\begin{array}{l}\text { A learner solves the problem but does not write the solution } \\
\text { in an appropriate form. }\end{array}$ \\
\hline
\end{tabular}

(Adapted from Nolting, 1998: 1)

The aforementioned types of errors have been used in the identification of learner errors in the content analysis of the three research questionnaires which forms part of data analysis.

Brodie (2005: 2-179) brought into the debate of learner errors "Situative" perspectives: Situative perspectives argue that what a learner says and does in the classroom make sense from the perspective of his/her current ways of knowing and being, his/her developing identity in relation to mathematics, and to his/her previous experiences of learning mathematics, both in and out of school.

After engaging with learners in class discussions of a particular topic, Brodie developed a coding scheme to categorize learners' contribution (Brodie as cited in Khan \& Chishti, 2011:656).

Table 2: Brodie's coding scheme to categorize learners' contribution (Brodie, 2005: 177)

\begin{tabular}{ll}
\hline Basic Error & $\begin{array}{l}\text { An error not expected at the particular grade level, indicates } \\
\text { that the learner is not struggling with the concepts that the } \\
\text { task is intended to develop, but rather with the other } \\
\text { concepts that are necessary for completing the task and } \\
\text { have been taught in previous years. }\end{array}$ \\
\hline Appropriate Error & $\begin{array}{l}\text { An incorrect contribution expected at the particular grade } \\
\text { level in relation to the task. }\end{array}$ \\
Missing Information & $\begin{array}{l}\text { Correct but incomplete and occurs when the learner } \\
\text { presents some of the information required by the task but } \\
\text { not all of it. }\end{array}$ \\
Partial insight & $\begin{array}{l}\text { Learner is grappling with an important idea which is not } \\
\text { quite complete nor correct, but shows insight into the task. }\end{array}$ \\
Complete correct & Provides an adequate answer to the task or question. \\
Beyond task & $\begin{array}{l}\text { Related to the task or topic of the lesson but go beyond the } \\
\text { immediate task and/or make some interesting connections } \\
\text { between ideas. }\end{array}$ \\
\hline
\end{tabular}

TD, 10(3), December 2014, pp. 340-354. 
Riccomini (2005: 233) brought into perspective (1) unsystematic errors: unintended, nonrecurring wrong answers which learners can readily correct by themselves; (2) systematic errors: though they are recurring wrong response methodologically constructed and produced across space and time, they are symptomatic of a faulty line of thinking that causes them to be referred to as misconceptions.

Elbrink (2008: 2) categorizes learners' mathematical errors into three main categories: calculation errors, procedural errors and symbolic errors. She elaborated on each of the categories: (1) as an error of numbers which she attributes to carelessness and lack of attention and further suggestes the possible solution to the calculating error is incorporation of an error checklist into a regular classroom routine and procedures. This will allow learners to assess themselves and identify repeated errors and mistakes in their work. (2) Learners are usually taught in drill and practice and automated to carry out specific mathematical tasks rapidly and effectively and can confuse that with conceptual understanding. Therefore they cannot recognize the importance of applying procedures correctly.

Procedural errors suggest that learners do not understand the concepts related to the procedure and are unable to build procedure from conceptual knowledge. She suggested the introduction of the concepts before the procedure, concrete manipulation and real-life application. In her elaborate discussion of procedural errors, she brought up the importance of the threshold concept which forms part of the theoretical framework of this study. Finally, (3) learners try to create meaning in the patterns of mathematical symbols and signs that they see in front of them rather than trying to understand. The identification of errors in the content analysis was based on the aforementioned errors. The errors described in Table 1 have been utilised to categorize the identified errors in this study. The procedural errors which were identified during content analysis could be eradicated from learners through teaching embedded on the threshold concept. One should, of course, acknowledge that errors are also a function of other variables in the education process which classifies errors according to information processing.

Inadequate flexibility in decoding and encoding new information involves incorrect interaction between single elements. Radatz (1979: 167) states:

Experience with similar problems will lead to a habit of rigid thinking; learners continue to use the cognitive operation they have developed even if the mathematical tasks have changed.

Difficulties due to incorrect association or rigidity of thinking are also common areas of errors in mathematics. Pippig as cited in Radatz (1979) further classified this type of error into:

1) Errors of perseveration, which is described as an error in which single elements of a task or problem predominates. Examples include: $9 \times 60=560 ; 7 \times 50000=35000$.

2) Errors of association, involving incorrect interactions between single elements. Examples include: $56+12=67 ; 6 \times 4=18$.

3) Errors of interference, in which different operations or concepts interfere with each other. The example that follows displays interference between the algorithms for addition and subtraction: $\quad 6845$ 
Here the learner added the digits in the units column, getting 15; added all but the top tens and hundreds column, getting 17 and 13 respectively and then subtracted to get the remaining two digits in the answer.

4) Errors of assimilation, in which incorrect hearing is attributed to the causes of reading and writing. Those errors are a result of lack of attention and concentration (random or careless errors).

5) Errors of negative transfer from the previous tasks, in which effects of erroneous impression from a set of exercises or word problems is visible.

The errors elaborated on above can be classified into four groups as in accordance with the previous studies. Figure 1 summarises the errors inferred from the previous literature above:

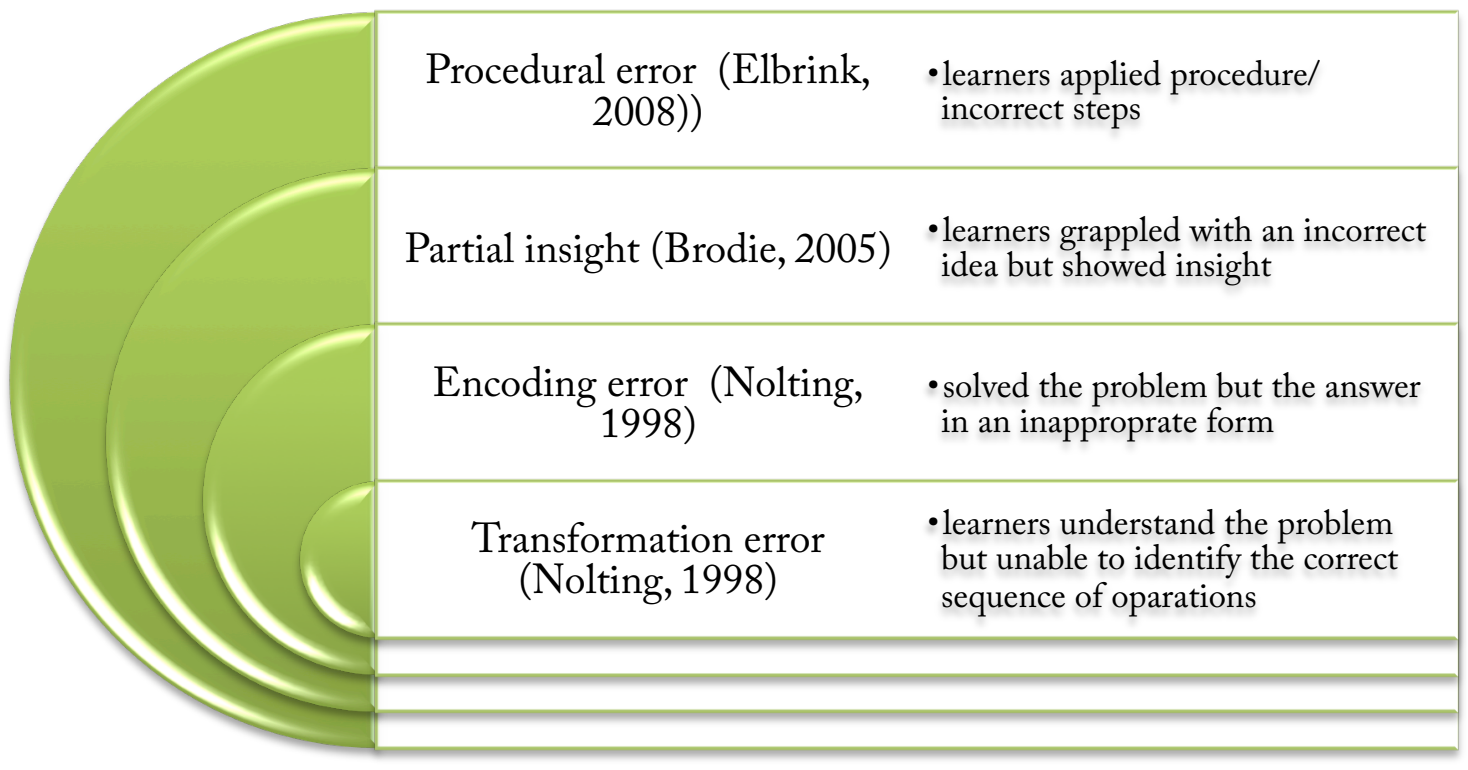

\section{Figure 1: Identified types of errors related to incorrect association and rigidity of thinking}

The aforementioned classification of errors summarises the types of errors related to incorrect association or rigidity of thinking which was drawn from the previous studies.

\section{Theoretical framework}

The researchers were guided by three theoretical frameworks: Polya's problem-solving techniques, threshold concepts and troublesome knowledge of Meyer and Land (2006), and Newman's error analysis in deconstructing the concept of error analysis.

\section{Polya's problem-solving techniques}

Polya developed four basic principles that need to be considered during problem solving. Based on the principles, the four steps that need to be followed during problem solving were developed later. The researchers identified a problem which sought to solve that particular problem; namely that learners continue to commit errors in financial mathematics. This might be attributed to the learners' problem-solving techniques; therefore understanding of the aforementioned theory can assist in eliminating the errors. Polya's theory of problem- 
solving techniques describes four steps to be followed during problem-solving in mathematics education. These steps seem to be relevant also to the learning of mathematical literacy.

According to Polya (1945), the following are the principles to be considered during problem solving:

First principle: Understand the problem

Learners might seem incompetent but maybe they did not fully understand the question.

Second principle: Devise a plan

There are many reasonable strategies to be employed in order to solve a particular problem. Polya states that the skill of choosing an appropriate strategy is best learnt through solving many problems.

Third principle: Carry out the plan

This is considered to be easier than devising a plan as it only needs the patience of executing the devised plan. This will include, for instance, correct substitution if the chosen strategy was the use of a formula. Consistency throughout the algorithms employed to arrive to the final answer is of utmost importance. If the devised plan does not work, you will have to discard it and use another one until you arrive at the correct answer.

Fourth principle: Look back

Taking time to reflect on your work enables you to predict the relevant strategy for solving a future problem.

The study sought answers as to why learners commit errors in financial mathematics and the underlying factors related to the type of errors they commit. The objectives of the study are based on Polya's theory on problem-solving techniques. If the teaching and learning process at schools could be influenced by the above-stated theory, both teacher and learners guided by the four-step principle, could dedicate more time to learners' work and thus reduce errors committed.

\section{Threshold concepts and troublesome knowledge}

Meyer and Land (2006: 1) argue that:

Threshold concept can be considered as akin to a portal, opening up a new and previously inaccessible way of thinking about something. It represents a transformed way of understanding, or interpreting, or viewing something without which the learner cannot progress.

It changes the way learners perceive learning, and the level of understanding of concepts is also improved. The acquisition of knowledge occurs through a process of gathering key concepts per particular subject. The concepts that are entrenched in learners' conceptual understanding therefore assist in problem solving.

According to Meyer and Land (2006: 4)

$A$ core concept is a conceptual 'building block' that progresses understanding of the subject; it has to be understood but it does not necessarily lead to a qualitative view of subject matter. 
As in the aforementioned discussion of Polya's problem-solving techniques, problem solving does not solely depend on the acquisition of concepts, but also depends on the choice of the relevant problem-solving technique.

After discussions with practitioners in a range of disciplinary areas, they came up with the following characteristics: threshold concepts are transformative, irreversible, integrative, bounded and troublesome (Meyer \& Land 2006: 5).

If threshold concepts could be developed in learners, that could build their confidence and therefore reduce the level of errors committed in problem solving.

Newman's Error Analysis

The researchers were guided by Newman's Error Analysis technique in the error analysis of learners' work. Newman's Error Analysis (NEA) provided a framework for considering the reasons that underlay the difficulties students experienced with mathematical word problems and a process that assisted teachers to determine where misunderstandings occurred. NEA also provided directions for where teachers could target effective teaching strategies to overcome them (White, 2010: 129-148). In search for underlying factors for learners committing errors and finding the suitable strategies to overcome them, the researchers were guided by NEA. By pinpointing the errors committed by learners in financial mathematics, teaching can be directed towards the correct procedure of solving the identified problem.

Newman's error analysis and follow-up strategies have helped learners with their problemsolving skills, and teachers developed a much more consistent approach to the teaching of problem solving.

According to White (2009:37),

Not only has it raised awareness of the language demands of problem solving, but through its systematic approach, teachers can focus on teaching for deeper understanding.

The afore-stated theory was also used in content analysis of the content-based questionnaire. NCTM (2006:60) states that

Students who have opportunities, encouragement, and support for speaking, writing, reading, and listening in mathematics classes reap dual benefits: they learn to communicate mathematically.

Various studies have been published on learner errors; the following section of the study will investigate learner errors identified from the review of other studies.

\section{Research methodology}

A positivist paradigm which included a quantitative approach was used for the measurement of data in order to discover and confirm causes and effects. The selection of the case purposively included one East London district school; however, the respondents were selected using a simple random sample technique.

Case study

Research was conducted with learners in Grade $10 \mathrm{ML}$ from a secondary school which the researchers conveniently chose in the East London district of the Eastern Cape Province in 
South Africa. The researchers considered the accessibility, travel costs and the time frame when choosing this particular school.

Sample size (n) and Justification

The school had 5 Grade 10 ML classes with 186 learners that is population (N) of Grade 10 ML. There are 104 girls and 82 boys with ages ranging from 14 to 18 years. The researcher adopted the simplified formula by Yamane (as cited by Israel, 2009) for proportions to determine the sample size (n).

Hence the sample size was nearly 105 where, $\mathrm{N}$ is the population size and assuming that confidence level is $95 \%$ and the level of precision is .5.

According to Cohen, Manion \& Morrison (2007: 97),

Determining the size of the sample will have to take account of attribution and respondent mortality, i.e. that some participants will leave the research or fail to return questionnaires.

Israel (2009: 2) states that

(B)ecause a proportion of .5 indicates the maximum variability in a population, this is often used in determining a more conservative sample size, that is, the sample size may be larger than the true variability of the population attribute were used.

After the sample size was determined, the respondents were selected by a simple random selection method.

Data-collection methods

Data was collected by means of structured-interview questionnaires with 4 Likert type questions and content based. These sought to uncover the underlying factors related to errors due to incorrect association or rigidity of thinking. Oppenheim (as cited in Cohen et al., 2007: 247) states that highly structured questionnaires and closed questions are useful in that they can generate frequencies of response amenable to statistical treatment and analysis.

\section{Data-collection instruments}

Two sets of structured-interview questionnaires were used; the first set was a content-based questionnaire where respondents were expected to work out financial mathematics problems, and the other set includes the possible underlying factors related to the different types of errors learners commit. The second questionnaire contained 4 Likert scale type of questions and was used as a follow-up questionnaire. This questionnaire was based on uncovering the underlying factors related to the errors due to incorrect association or rigidity of thinking.

\section{Data analysis}

In the first questionnaire which is content based, the researchers were guided by the Newman's error analysis in content analysis and identification of errors committed. Quantitative analysis with descriptive statistics which describe the distribution, the relationship among variables and variability through the use of frequencies was used to analyse the second questionnaire. Statistical Package for Social Sciences (SPSS) version 21 was used for correlation coefficient analysis to measure the relationship between variables of 
each of the afore-stated research questions. Corrolation analysis (ANOVA) was used for testing the hypotheses of the study.

\section{Management of TYPE I and TYPE II Errors in data analysis}

The researchers were mindful of the place and significance of test, not forgetting the problem of the Hawthorne effect operating negatively or positively on students who have to undertake the tests (Cohen et al., 2007: 116). The Hawthorne effect is the phenomenon in which participants alter their behaviour as a result of being part of the study. The researchers ensured standardized procedures in administering the test. In the data-analysis stage, the researchers avoided TYPE I and / or TYPE II errors by presenting the data without misrepresenting its meaning. By a pilot study the researchers ensured the invalidity is minimized as much as possible throughout the study. That shows that validity of the study cannot be achieved through tests only, but when the results of different tools (i.e. tests and questionnaires) used should be analysed concurrently.

According to Cohen et al. (2007:117),

For research to be reliable it must be carried out on a similar group of respondents in a similar context (however defined), then similar results would be found.

To test the reliability and validity of the instruments, the questionnaires will be developed and administered as a pilot study.

Correlation analysis results

Table 3 below illustrates the Pearson correlation $(r)$ and significance ( $p$-value) of the four variables of this particular research question.

Table 3: Summary of the correlation analysis of each variable

\begin{tabular}{lllll}
\hline & & A & B & C \\
\hline A & Pearson Correlation & 1 & .045 & .069 \\
& Sig. (1-tailed) & & .325 & .242 \\
B & Pearson Correlation & .045 & 1 & .171 \\
& Sig. (1-tailed) & .325 & & .040 \\
C & Pearson Correlation & .069 & .171 & 1 \\
& Sig. (1-tailed) & .242 & .040 & \\
\hline
\end{tabular}

NOTE: the variables of research question 2 were labelled A - C for the writer's convenience in constructing the following table which summarises the correlation and the significance of the stated variables.
A - I confuse addition with multiplication
B - I forget to write units
C-I write down an incorrect number

The correlation analysis was conducted to examine the relationship between learners forgetting to write units (B) and learners writing down an incorrect number/figure (C). The analysis was significant, $p=.04(r=+.17)$ which illustrated a weak correlation between the afore-stated variables. Learners confusing addition with multiplication (A) and learners writing down an incorrect number (C) illustrated non-significance and weak correlation, as $p$ $=.242(r=+.07)$. 
The correlation analysis was conducted to examine the relationship between learners confusing addition with multiplication (A) and learners forgetting to write units (B) was not significant, $p=.325,(r=+.05)$ which illustrated a weak correlation.

Table 4: Descriptive statistical analysis

\begin{tabular}{lrrrr}
\hline & N & Std. Deviation & \multicolumn{2}{r}{ Skewness } \\
& Statistic & Statistic & Statistic & Std. Error \\
I confuse addition with multiplication & 105 & .908 & -.648 & .236 \\
I forget to write units & 105 & .978 & -.101 & .236 \\
I write down an incorrect number & 105 & .944 & .812 & .236 \\
Valid N (listwise) & 105 & & & \\
\hline
\end{tabular}

According to Garson (2012: 17),

A common rule-of-thumb test for normality is to run descriptive statistics to get skewness and kurtosis. Skewness should be within +1 to -1 .

Normality: All the sub-variables of the incorrect association or rigidity of thinking have met the Normality assumption as all the Skewness Statistic value are within the range of -1 and +1 .

Homogeneity: The afore-stated research question has met the Homogeneity Assumption as the highest value of the Standard Deviation $0.978 \div 0.908=1.077092511$ which is not greater than 2 .

Based on the analysis of second questionnaire which sought to answer the research question "what are the underlying factors related to errors due to incorrect association or rigidity of thinking?", it revealed that $63.8 \%$ of the respondents admitted to confusing the addition sign with the multiplication sign, but $60 \%$ only did that occasionally as against $3.8 \%$ who admitted to always making that error.

From 105 respondents, $50.5 \%$ forgot to write units whereas only $7.6 \%$ always committed such an error, and $42.9 \%$ admitted to occasionally committing such an error.

Learners would write an incorrect number or digit when transcribing from their rough work, $29.5 \%$ of the respondents attested to sometimes committing this type of error, with $1.9 \%$ always doing that.

\section{Discussion}

The afore-mentioned results illustrated a weak relationship between learners forgetting to write units and those writing down an incorrect number when transcribing from the rough paper, and a significance $p<.05$, which represent only a third $(33.3 \%)$ of the variables of the underlying factors related to errors due to incorrect association or rigidity of thinking. All the other variables illustrated no significance, but a weak correlation cannot be generalized to a broader population. The fact that the correlation of variables in this research question accounted for $33.3 \%$ indicated that they have no significant effect on the research question.

According to Radatz (1979: 167), 
Inadequate flexibility in decoding and encoding new information often means that experience with similar problems will lead to habitual rigidity of thinking.

Learners develop cognitive operations and continue to use them even if those are no longer relevant.

Respondents were given Questionnaire 1 which consisted of five simple or compound interest questions, which was analyzed through marking and content analysis. When given simple and compound interest problems, $83 \%$ of the respondents applied a formula which was either relevant or irrelevant. Drawing from the theoretical framework of the study; threshold concept is known to be irreversible. Once a learner understands the concept it is unlikely to be forgotten. The use of formula, even if not taught, is the result of the afore-stated characteristic of threshold concept. They may have drawn the formulae from Grade 9 knowledge, without noticing that in this case they were expected to apply a multi-step procedure to find the correct answer. Radatz (1979) describes this as related to incorrect association or rigidity of thinking. Some errors identified in the content analysis, where a learner would confuse addition with multiplication, are classified by Nolting (1998) as Transformation error. Some would add instead of multiply even though they followed the correct steps and that, according to Nolting (1998) and Elbrink (2008), is classified as Procedural error. The researcher classifies this type of error as an error due to incorrect association as the respondents demonstrated error of assimilation because they knew the correct algorithms, but confused the multiplication sign with the addition sign.

Based on the frequency table which summarises learner responses, it could be ascertained that the majority ( $\mathrm{n}=63,60 \%$ ) of learners admitted to sometimes confusing addition with multiplication. This was also evident in their responses analysed through content analysis where a number of errors related to the afore-stated factor were identified.

Only $7.6 \%$ admitted to always forgetting to write the units in their final answers whereas $42.9 \%$ sometimes made that error. Based on the correlation analysis previously illustrated, learners forgetting to write units was significant but with a weak correlation to writing an incorrect value. It is the only variable out of three $(33.3 \%)$ of the variables for the stated research question that was revealed to be significant. Forgetting to write units in the final answer in financial mathematics is a common error committed and is evidently supported by the frequency tables.

Content analysis revealed that learners were introduced to the use of simple and compound interest formula in the previous grades. In their attempts to work-out simple and compound interest problems, they would use the formula. The majority of learners ( $\mathrm{n}=89,84.8 \%)$ used formulae to answer the simple and compound interest problems. In using the formula, others would use an incorrect formula and that, according to Brodie (2005), is Partial Insight described as the learners demonstrating that they grappled with an idea but showed insight in the task.

The respondents strongly disagreed with writing down an incorrect value or digit when working out financial mathematics problems. Only a few $(n=2,1.9 \%)$ admitted to always committing that error and it was not related to any of the variables indicated.

The following is the summary of the errors identified from content analysis:

- Use of formula even though it was not appropriate. Learners were supposed to follow a multi-step procedure without the use of the formula when working out the final 
amount in simple and compound interest. As discussed in the previous sections, this was attributed to the irreversible characteristic of threshold concept.

- Use of an incorrect formula, where learners used a formula for calculating the final amount (A) with simple interest instead of using only the simple interest (SI) formula.

- Incorrect substitution in the formula. According to Nolting (1998) that is regarded as transformation error and he describes it as occurring when a learner understands what is required but is unable to employ the sequence of operations needed to solve the problem. The majority of the learners substituted the value of $i$ (interest rate) incorrectly not taking into account that $i$ is a percentage.

- Learners converted the period and the interest rate to months even if one of them was already given in months. That is also attributed to the drill and practise method used by educators where "you divide $i$ (interest rate) by 12 and multiply $n$ (period) by 12 if the interest is compounded monthly". Learners apply the rules entrenched in the drill and practise method in class. In elaborating on the phenomenon Soendergaard and Cachaper (2008) brought into perspective a concept instrumental understanding which they describe as demonstrated by someone who uses rules without understanding.

- Even though some employed the correct algorithms, they incorrectly rounded off the final answer. The researcher classifies that type of error as a Placement error which is a particular type of procedural error. Nolting (1998) describes this type of error as incorrect sequencing of digits or alignment of algorithms.

The following are the errors identified through correlation analysis of Questionnaire 2:

$>$ Learners forgetting to write units and writing down incorrect digits showed significance and a weak correlation between the two variables.

$>$ Learners forgot to write units in the final answer.

$>$ Learners wrote down incorrect values when transcribing their rough work. This could be attributed to the fact that they panicked and felt rushed.

Out of 3 variables in the afore-stated research question, only the above proved to be significant (33.3\% significant) and illustrated a weak correlation.

\section{Research implications}

\section{Theoretical implication of the study}

The study was guided by three theoretical frameworks:

1) Polya's problem-solving techniques which guided the researcher in identifying, planning, execution of the plan and reviewing the identified factors related to learner errors.

2) The threshold concept forms a fundamental part of error analysis as most of the errors were associated with entrenched knowledge from the previous grades. This was evident in the content analysis.

3) Newman's Error Analysis guided the researcher in the content analysis of Questionnaires 1 and 2 that sought to identify the type of errors committed by learners and the underlying factors related to those errors. It gave learners an opportunity to reflect on the errors. 


\section{Conclusions}

Error analysis may be incorporated in the teacher training curriculum as it will assist in reducing or eliminating learner errors. It will assist educators to be able to identify learner errors, assist learners in eliminating those errors and encourage learners to review the work before submission. Understanding learners' rationale when going through their work can also assist teachers to institute remedial lessons. Educators need to incorporate error analysis in their lesson designs, as knowledge of why learners commit errors is valuable to the educators as it will help in selecting the relevant strategies.

Learners should be taught to apply Polya's problem-solving techniques. That will train them in applying the techniques to make sure they understand the question before attempting to answer it; to plan before answering; to answer and then review what was written to make sure that they reduce the errors committed.

\section{Recommendations of further research in financial mathematics error analysis}

Further research studies could be conducted in error analysis in financial mathematics, but the focus should be on Grades 11 and 12 as learners continue to commit these kinds of errors, even in these grades. The study population could be increased to a number of schools ( 5 or more schools) to increase the reliability and validity of the research findings.

Error analysis is a topic that has not yet been exhausted in South Africa in both mathematics and Mathematical Literacy. More studies need to be conducted so it can provide recommendations to assist educators in their lesson designs in order to assist learners in avoiding the identified errors. That could improve the learner performance in mathematics and Mathematical Literacy.

Further research study should be conducted on the use of formula in working out financial mathematics problems in Mathematical Literacy. Educators and learners still perceive the use of formula relevant and convenient when working out simple and compound interest problems. The study should be focused on Grades 10 and/or 11.

The educators' understanding of the Curriculum Assessment Programme Statement (CAPS) in Mathematical Literacy needs to be interrogated further as some of learner errors could be attributed to educators' lack of understanding of the curriculum. Most educators seem not to understand the Curriculum Assessment Programme Statements, even though this has already been rolled out in Grades 10, 11 and 12. Educator training has been rolled out in the past three years $(2010-2013)$ throughout the provinces, but teachers do not appear to understand the content entailed and its purpose.

\section{References}

Brodie, K. (2005). Using cognitive situative perspective to understand teacher interaction with learner error. Proceedings' of the $29^{\text {th }}$ Conference of the international Group for the Psychology of Mathematics Education, 2, 177-184.

Cohen, L., Manion L., \& Morrison K. (2007).Research Methods in Education,(6 ${ }^{\text {th }}$ ed.). New York: Routledge Falmer.

Department of Basic Education Republic of South Africa. (2011). Curriculum and Assessment Policy Statements (CAPS).

TD, 10(3), December 2014, pp. 340-354. 
Eibrink, M. (2008). Analyzing and Addressing Common Mathematical Errors in Secondary Education. B. S Undergraduate Mathematical Exchange, 5(1), 2-4.

Garson, G. D. (2012). Testing Statistical Assumptions. G. David Garson and Statistical Associates Publishing. Florida: USA.

Heinze, A \& Reiss, K. (2007). Mistake-Handling Activities in Mathematics Classroom: Effects of an In-service Teacher Training on Students' Perfomance in Geometry. Institute of Mathematics. University of Murnich, Germany.

Israel, G. D. (2009). Determining the Sample Size. Program Evaluation and Organisational Development. IFAS, University of Florida. PEOD-6.

Khan, S. B. \& Chishti, S. (2011). Learners' Errors: supporting learners for participating in Mathematics classroom, International Journal of Academic Research, 3(1) Part II: 655658.

Meyer, J.H.F.\& Land, R. (2006). Threshold Concepts and Troublesome Knowledge 1 Linkages to Ways of Thinking and Practising' in Improving Student Learning - Ten Years On. C. Rust (Ed), OCSLD, Oxford.

Murray, H. (2012). Problems with Word Problems in Mathematics. Learning and Teaching Mathematics, 13, 55-58.

National Council of Teachers of Mathematics. (2000). Principles and Standards for School Mathematics. Reston, VA: NCTM, 2000.

Nolting, P. D. (1998). The Invertiture controversy. 28(4). $22-30$.

Peng, A. (2009). Teacher knowledge of students' mathematical errors. Sweden: Umea Mathematics Education Research Centre, Umea University.

Polya, G. (1945). The Four-step Problem-solving Process. [On-line]: Available url: http://home.comcast.net/ mrtwhs/mash/polya.pdf.Accessed: 24 May, 2012.

Radatz, H. (1979). Journal for Research in Mathematics Education,National Council of Teachers of Mathematics. [On-line]: Available url: http://www.jstor.org/stable/748804. Accessed: 20 July, 2011.

Riccomini, P. J. (2005). Identification and remediation of systematic error partterns in subtraction. Learning Disability Quarterly. 28(3). 1 -10.

Sheinuk, L.C. (2010). Intermediate phase mathematics Teachers reasoning about learners' mathematical thinking. Unpublished Master of Education thesis, Wits School of Education, Johannesburg, South Africa.

Soendergaard, B. D. and Cachaper, C. (2008). Teaching Mathematics effectively to primary studentsin developing countries: Insights of Neuroscience and Psychology of Mathematics. GPE Working Paper series on Learning. 2(5) 11 - 18.

White, A.L. (2010). Numeracy, Literacy and Newman's Error Analysis: Journal of Science and Mathematics Education in Southeast Asia, 33(2), 129-148.

White, A. L. (2009). Newman's Error Analysis' Impact Upon Numeracy and Literacy. University of Western Sydney: al.white@uws.edu.au. Accessed: 20 July, 2012. 